\title{
Conventional bioprocesses for the removal of gas-phase contaminants
}

\author{
Carol Wambugu, Adjei Danso Marvins, Jewel Das and Eldon R. Rene* \\ IHE Delft Institute for Water Education, Westvest 7, 2601DA Delft, The Netherlands
}

Volatile organic compounds (VOCs) are among the most common air pollutants emitted from a variety of point and non-point sources, including process industries, automobiles and urban land surfaces. VOCs are primary precursor to the formation of ground level ozone and they play a major role in facilitating atmospheric photochemical reactions, leading to serious environmental hazards. Therefore, from an environmental perspective, it is necessary to limit and control these emissions as they affect climate change, growth of plants and overall the health of human beings and all life forms. The known health effects in humans may include, irritation to the respiratory tracts, eye and nose, damage to liver, kidney and the central nervous system, as well as allergic skin reactions.

In order to limit the discharge of VOCs to the atmosphere and to prevent further deterioration of air quality, stringent regulations have been implemented in many developing and developed countries. Meeting the regulatory standards has been a major challenge for polluting industries, environmental professionals/researchers and plant managers. Besides reducing these emissions at their source, various physico-chemical and biological techniques are available for the treatment of waste-gas streams containing VOCs. In some specific cases, depending on the pollutant loading rate $\left(\mathrm{g} \mathrm{VOC} / \mathrm{m}^{3} . \mathrm{h}\right)$, combinations of techniques may be required to reduce the pollutant levels below the regulatory discharge limits. From a cleaner production/practice viewpoint, it is advisable to follow the "preventative approach", rather than to minimize or mitigate the effects of toxic VOCs. For instance, in the oil industry, the use of harmful chemical substances for drilling fluids, lubricants, surfactants, sulphide removers, among others, can be replaced by using environmentally friendly solutions.

Biological treatment of waste-gases and odours has proven to be an effective and economical option for the treatment of gasphase pollutants at low concentrations and high gas-flow rates [1-9]. Biotechnologies for waste-gas treatment exploits the ability of a suitable biocatalyst to mineralize the contaminants present in air. The organic contaminants (e.g. methanol) are utilized by the microbes as a source of carbon and energy. It is noteworthy to mention that, not only organic compounds, but also inorganic compounds (e.g. hydrogen sulphide) can be effectively removed using biological wastegas treatment systems. The most widely used bioreactor configurations are the biofilter, the biotrickling filter and the bioscrubber [1-9].

Biofilters, for the past 60-70 years, have been used to control odours from wastewater treatment plants, sewerage works, composting plants, and for the removal of VOCs from contaminated air $[1,6,8]$. In this bioreactor configuration, a contaminated air stream is humidified and passed in an up-flow or down-flow direction through a packed bed containing mixed microbial cultures (Figure 1). In presence of oxygen, the biodegradable pollutant is converted into less toxic compounds like carbon dioxide, water and organic matter (biomass). The packing material, moisture content, temperature and $\mathrm{pH}$ are the most important conditions for effective operation (i.e. longevity) of the biofilters. If the waste-gas stream contains chlorinated VOCs or hydrophobic VOCs, the pollutant loading rate and/or the inflow concentration strongly affects the efficiency of the biofilter. In specific cases, depending on the composition of the waste-gas, biocatalysts can show selective biodegradation of the individual pollutants. The lack of a constantly trickling/flowing liquid-phase, usually the medium containing nutrients and trace elements, makes the biofilter somewhat ineffective for the removal of hydrophilic pollutants. To overcome these limitations, several innovative configurations can be used. These include the use of hybrid biofilters (combined physico-chemical + biological process), two-stage biofilters, split feeding strategies and the use of thermophilic biofilters operating in the range of $45-70^{\circ} \mathrm{C}[4-6,8]$.

Biotrickling filters are effective for the treatment of hydrophilic VOCs and other odorous pollutants such as hydrogen sulphide. In biotrickling filters, the waste-gas stream is passed over a microbial consortium immobilized on an inert support media having high

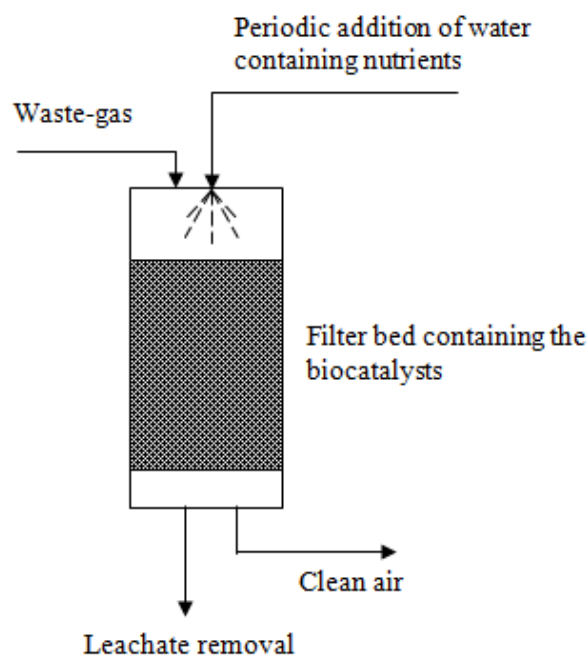

Figure 1. Schematic of a biofilter for VOC removal.

Correspondence to: Eldon R. Rene, IHE Delft Institute for Water Education, Westvest 7, 2601DA Delft, The Netherlands, Tel: +31-152151840; E-mail: e.raj@un-ihe.org

Received: May 22, 2017; Accepted: June 08, 2017; Published: June 10, 2017 
specific surface area and porosity (Figure 2). The process of gas absorption, gas diffusion into the biofilm, liquid-phase regeneration and subsequent biodegradation occurs simultaneously in one process apparatus. A continuous stream of recirculating water containing the essential nutrients for microbial growth is distributed evenly over the filter bed. The waste-gas stream passes through the biotrickling, either co- or counter current to the liquid flow and supplies the essential carbon source for the biocatalysts $[3,4,7,9]$. The factors affecting the pollutant removal efficiency in a biotrickling filter can be summarized as follows: (i) composition and concentration of the waste-gas stream, (ii) configuration and properties of the packing material, (iii) trickling liquid flow pattern, (iv) nutrient composition, (v) formation of intermediates/metabolic end-products, (vi) $\mathrm{pH}$, (vii) empty bed residence time, and (viii) temperature.

Bioscrubbers are particularly effective for the removal of odours and hydrophilic VOCs from waste-gases. It consists of a first-stage absorption tower and a second-stage suspended growth bioreactor (Figure 3). Polluted air is passed through the absorption tower in which the air pollutants are absorbed and/or stripped by a continuously falling aqueous solution $[2,3,8]$. Biological oxidation of the absorbed pollutants occurs in the suspended growth bioreactor. Bioscrubber is suitable for the removal of hydrophilic pollutants and it can be operated at high gas loading rates. From an application view-point, a bioscrubber offers numerous advantages due to its robustness, sustainability and its ability to withstand higher odour concentrations under severe fluctuating conditions. Moreover, it can be operated at high pollutant loading rates.

However, it has some drawback such as its low abatement performance for hydrophobic VOCs and high investment costs as compared to the biofilter and the biotrickling filter. There are also few challenges such as the generation of excess sludge (biomass), its accumulation and disposal and problems with gas-liquid mass transfer if the waste-gas contains hydrophobic VOCs $[8,9]$. These challenges

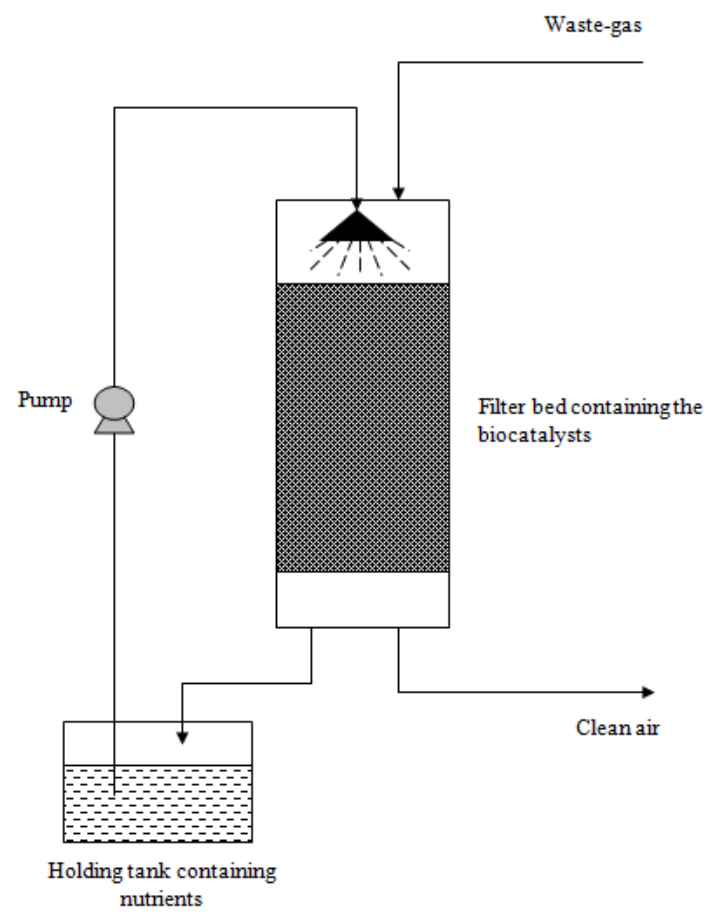

Figure 2. Schematic of a biotrickling filter for VOC removal.

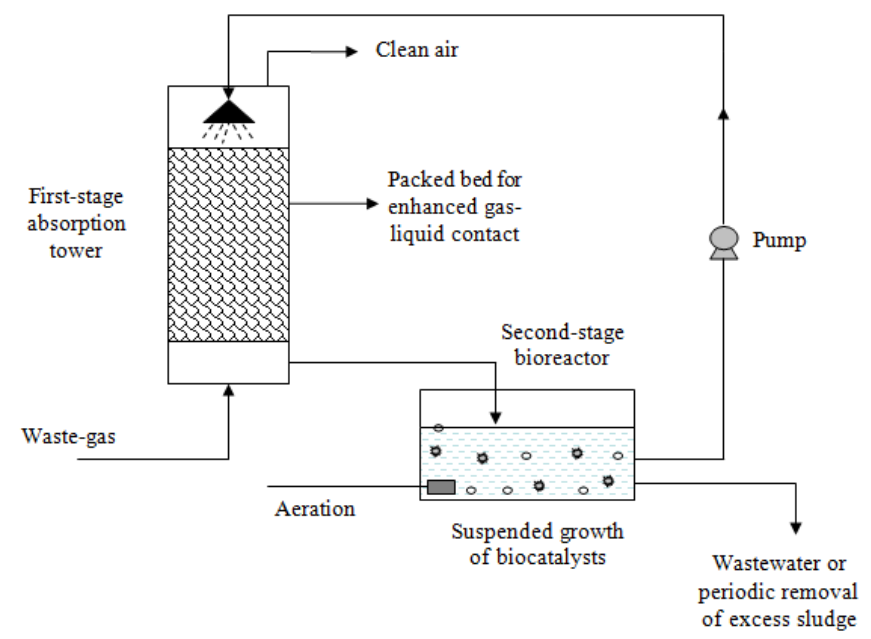

Figure 3. Schematic of a bioscrubber for VOC removal.

can be easily overcome by improving the bioreactor design, altering the pollutant feeding strategy (split-feed, intermittent, cyclic), using well-acclimated biocatalysts or a fungal-bacterial consortia and using sensors for improved bioreactor monitoring and process control.

\section{References}

1. Ferdowsi M, Avalos Ramirez A, Jones JP, Heitz M (2017) Elimination of mass transfer and kinetic limited organic pollutants in biofilters: A review. International Biodeterioration and Biodegradation 119: 336-348.

2. Frutos OD, Quijano G, Pérez R, Muñoz R (2016) Simultaneous biological nitrous oxide abatement and wastewater treatment in a denitrifying off-gas bioscrubber. Chemical Engineering Journal 288: 28-37.

3. Kennes C, Rene ER, Veiga MC (2009) Bioprocesses for air pollution control. Journal of Chemical Technology and Biotechnology 84: 1419-1436.

4. López ME, Rene ER, Malhautier L, Rocher J, Bayle S, et al. (2013) One-stage biotrickling filter for the removal of a mixture of volatile pollutants from air: Performance and microbial community analysis. Bioresource Technology 138: 245252. [Crossref]

5. López ME, Rene ER, Boger Z, Veiga MC, Kennes C (2017) Modelling the removal of volatile pollutants under transient conditions in a two-stage bioreactor using artificial neural networks. Journal of Hazardous Materials 324: 100-109. [Crossref]

6. Mohammad BT, Rene ER, Veiga MC, Kennes C (2017) Performance of a thermophilic gas-phase biofilter treating high BTEX loads under steady- and transient-state operation. International Biodeterioration and Biodegradation 119: 289-298.

7. Montebello AM, Mora M, López LR, Bezerra T, Gamisans X, et al. (2014) Aerobic desulfurization of biogas by acidic biotrickling filtration in a randomly packed reactor. Journal of Hazardous Materials 280: 200-208. [Crossref]

8. Rene ER, Veiga MC, Kennes C (2012) Combined biological and physicochemical waste-gas cleaning techniques. Journal of Environmental Science and Health, Part AToxic/Hazardous Substances and Environmental Engineering 47: 920-939. [Crossref]

9. Rodriguez G, Dorado AD, Fortuny M, Gabriel D, Gamisans X (2014) Biotrickling filters for biogas sweetening: Oxygen transfer improvement for a reliable operation. Process Safety and Environmental Protection 92: 261-268.

Copyright: (C2017 Wambugu C. This is an open-access article distributed under the terms of the Creative Commons Attribution License, which permits unrestricted use, distribution, and reproduction in any medium, provided the original author and source are credited. 